\title{
The Effects of Chronic AC Magnetic Field on Contraction and Relaxation of Isolated Thoracic Aorta Rings of Healthy and Diabetic Rats
}

\author{
Işıl Öcal* and İsmail Günay \\ Cukurova University; Medical Faculty; Biophysics Department; iocal@cu.edu.tr; Balcali - Adana - Turkey
}

\begin{abstract}
The aim of in this study was to determine the effect of chronic alternating current (AC) magnetic field on the contraction and relaxation parameters of isolated thoracic aorta rings in healthy and diabetic rats. Sixty rats (Wistar albino spp) weighing between 250-300 g were used. The rats were divided into four groups: 1 -Control (C), 2- control + magnetic field $(C+M A), 3$ - experimental diabetic (DIA), 4- experimental diabetic and magnetic field (DIA+MA). Magnetic fields of $5 \mathrm{mT}$ intensity and $50 \mathrm{~Hz}$ frequency oriented in the north-south direction was applied to the C+MA and DIA + MA groups for 2 hours each day for one month, after which rats were killed by decapitation and the thoracic aorta dissected. This showed attenuated contraction responses to phenylephrine (PE) and elevated relaxation responses to acetylcholine (ACh) of the thoracic aorta rings of rats in the C+MA and DIA+MA groups compared to group $C$ but no changes in the relaxation responses to sodium nitroprruside (SNP) of thoracic aorta rings relative to group $C$ and DIA. The weights of rats in DIA+MA or C+MA groups compared to the DIA and $C$ groups decreased.
\end{abstract}

Key words: Magnetic field, diabetic rats, thoracic aorta, endothelium-depending and endothelium-independing relaxation, endothelium-derived hyperpolarizing factor (EDHF), endothelium-derived relaxing factor $(E D R F)$

\section{INTRODUCTION}

The acute and chronic positive and negative effects of magnetic fields on living organisms are among the contemporary research topics. Medicine has also made use of the effect of magnetic fields. Bellossi et. al. (1996, 1998), have demonstrated that the blood cholesterol, glucose and triglyceride levels of diabetic rats were lowered by acute exposure to magnetic field. Gordon et al. (1981), on the other hand showed the selective effect of alternating electromagnetic fields on atherosclerotic lesions without harming the blood vessels, by demonstrating the biophysical changes caused by electromagnetic fields on the atherosclerotic plaques which led to their suggestion that this could serve as a new field in the selective treatment of atherosclerosis.

In this study, the effect of chronic exposure to AC magnetic fields on the contraction and relaxation of the thoracic aorta preparations in both the healthy and the diabetic rat was investigated.

\section{MATERIALS AND METHODS}

In this study, 60 albino Wistar spp rats weighing between 250-300 g were used. They were divided

\footnotetext{
* Author for correspondence
} 
into four groups as, control $(\mathrm{C}, \mathrm{n}=15)$, diabetic $(\mathrm{D}$, $\mathrm{n}=15)$, control + magnetic field $(\mathrm{C}+\mathrm{MA}, \mathrm{n}=15)$ and the diabetic + magnetic field (DIA+MA, $n=15)$.

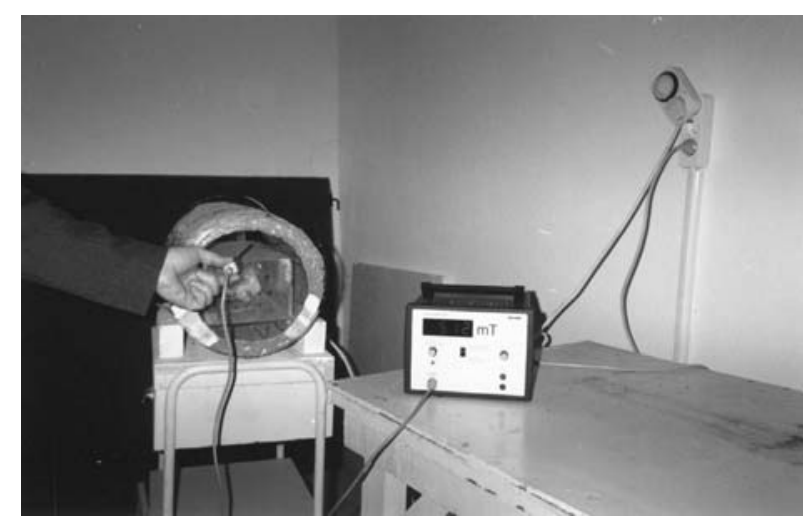

The $\mathrm{C}$ group was formed by injecting $1 \mathrm{ml} / \mathrm{kg}$ of citrate buffer $(\mathrm{CB})$ into the jugular veins whereas the DIA group was formed by injecting $45 \mathrm{mg} / \mathrm{kg}$ streptozotocin (STZ) into the jugular veins of the rats. The $\mathrm{C}+\mathrm{MA}$ and $\mathrm{DIA}+\mathrm{MA}$ groups were formed by exposing the rats to a $5 \mathrm{mT}$ intensity, 50 $\mathrm{Hz}$ frequency, north-south oriented modulation magnetic field for 2 hours a day. The rats in each group were weighed once a week for the onemonth study period (Figs. 1 and 2).

Figure 1 - The source of magnetic field and teslameter.

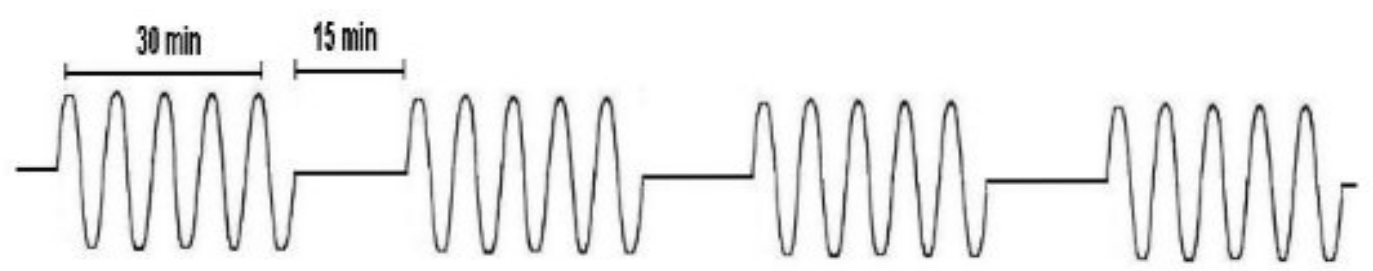

Figure 2 - Modulated magnetic field.

The rats were killed by decapitation after one month and their thoracic aorta preparation was isolated. The 3-4 mm long thoracic aorta rings prepared were fixed onto two parallel wires maintained in a bath containing the Kreb's solution. The temperature of the bath was maintained at $37 \pm 1{ }^{\circ} \mathrm{C}$ and aerated continuously with a gas mixture of $95 \% \mathrm{O}_{2}+5 \% \mathrm{CO}_{2}$. After a 2 hour period of rest, the concentration of the organ bath medium was changed with $10^{-7} \mathrm{M}$ PE for $\mathrm{F}$ and $10^{-6} \mathrm{M}$ ACh and SNP for relaxation. The F and relaxation were recorded in a Grass Model 7 Polygraph by means of a Grass $\mathrm{FTO}_{3}$ forcedisplacement transducer.

The results were expressed as average \pm SEM for the contraction force $\mathrm{F}(\mathrm{mg})$ and relaxation value (\%). The data obtained were evaluated using the unpaired Students' t-test.

\section{RESULTS}

Comparison of the weights of the rats showed increases in the $\mathrm{C}$ and $\mathrm{C}+\mathrm{MA}$ groups (Fig. 3) decrease in DIA and DIA+MA groups (Fig. 4) after one month (Table 1).

In the thoracic aorta rings of the rats in the $\mathrm{C}$ and $\mathrm{C}+\mathrm{MA}$ groups, comparison of the $\mathrm{F}$ showed attenuation by $\mathrm{PE}$ and the relaxation was augmented by ACh with SNP showing no effect (Figs. 5 and 6). Comparison of the rats in the DIA and DIA+MA groups showed attenuation of the F whereas the relaxation was augmented by $\mathrm{ACh}$ with SNP showing no effect (Figs. 5 and 6). The differences were statistically significant (Table 2). 
Table 1 - The average weights (g) and SEM values for the C, C+MA, DIA, DIA+MA groups measured once a week during the one-month period.

\begin{tabular}{lrrrrr}
\hline \multirow{2}{*}{ Groups } & \multicolumn{5}{c}{ Weeks } \\
\cline { 2 - 6 } & $\mathbf{0}$ & $\mathbf{1}$ & $\mathbf{2}$ & $\mathbf{3}$ & $\mathbf{4}$ \\
\hline C & $259 \pm 4$ & $264 \pm 8$ & $281 \pm 3$ & $290 \pm 4$ & $306 \pm 8$ \\
C+MA * & $262 \pm 4$ & $280 \pm 6$ & $287 \pm 7$ & $305 \pm 5$ & $317 \pm 6$ \\
\hline DIA & $289 \pm 7$ & $271 \pm 4$ & $253 \pm 6$ & $235 \pm 7$ & $221 \pm 7$ \\
DIA+MA* & $289 \pm 7$ & $282 \pm 7$ & $271 \pm 7$ & $261 \pm 9$ & $256 \pm 10$ \\
\hline p $<0.001$ & & & & &
\end{tabular}

Table 2 - The average and SEM values of the F induced by the $10^{-7} \mathrm{M}$ PE solution and the percentage relaxation induced by the $10^{-6} \mathrm{M} \mathrm{ACh}$ and SNP on the isolated thoracic aorta preparations for the C, C+MA, DIA and DIA+MA groups.

\begin{tabular}{lrrr}
\hline \multirow{2}{*}{ Groups } & \multirow{2}{*}{ F (mg) } & \multicolumn{2}{c}{ \% Relaxation } \\
\cline { 3 - 4 } C & $1388.3 \pm 4$ & $59.9 \pm 2$ & SNP \\
C+MA * & $1318.6 \pm 5$ & $78.7 \pm 3$ & $69.0 \pm 2$ \\
\hline DIA & $945.3 \pm 5$ & $19.1 \pm 1$ & $69.0 \pm 2$ \\
DIA+MA* & $653.2 \pm 5$ & $53.7 \pm 2 *$ & $74.4 \pm 2$ \\
$* \mathrm{p}<0.001$ & & & $74.4 \pm 2$ \\
\hline
\end{tabular}

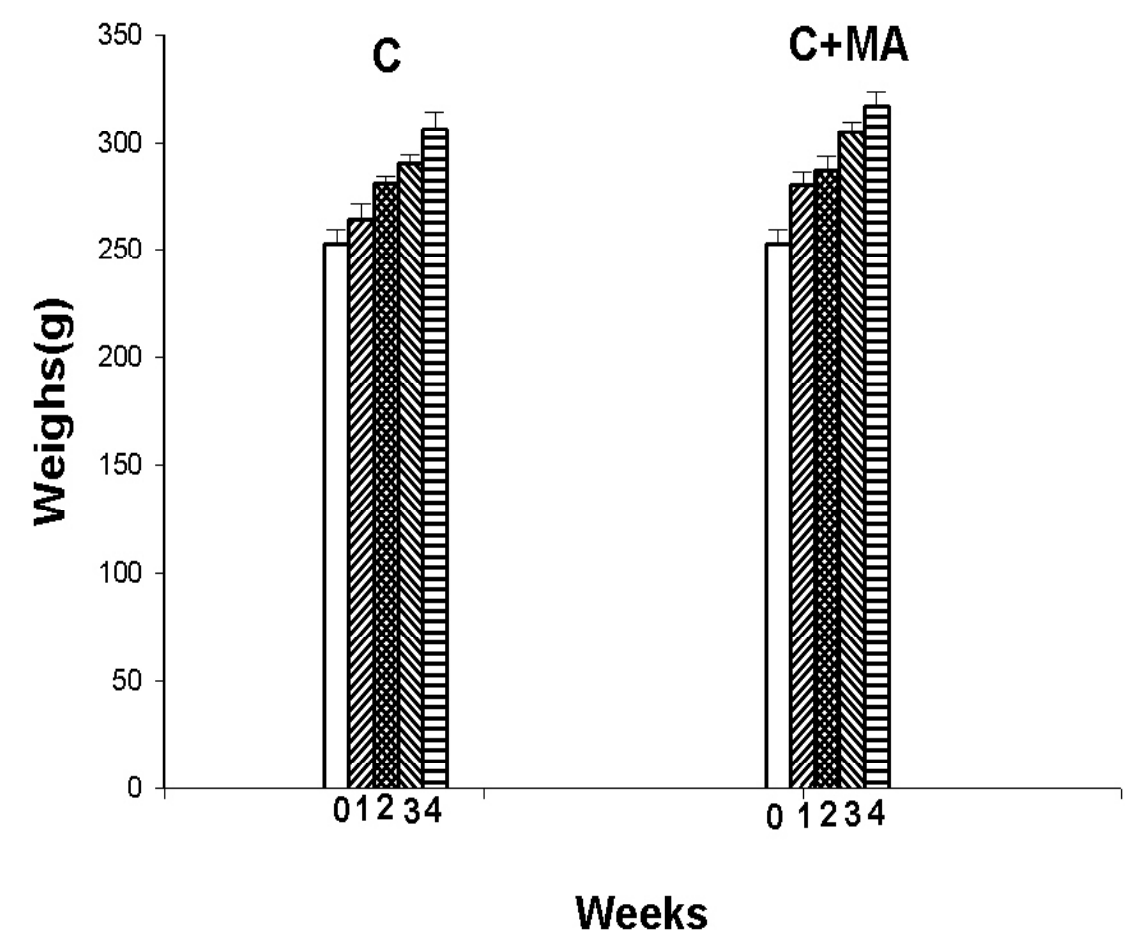

Figure 3 - The weigths of rats in $\mathrm{C}$ and $\mathrm{C}+\mathrm{MA}$ groups during one month (mean $\pm \mathrm{SEM}$ ) 


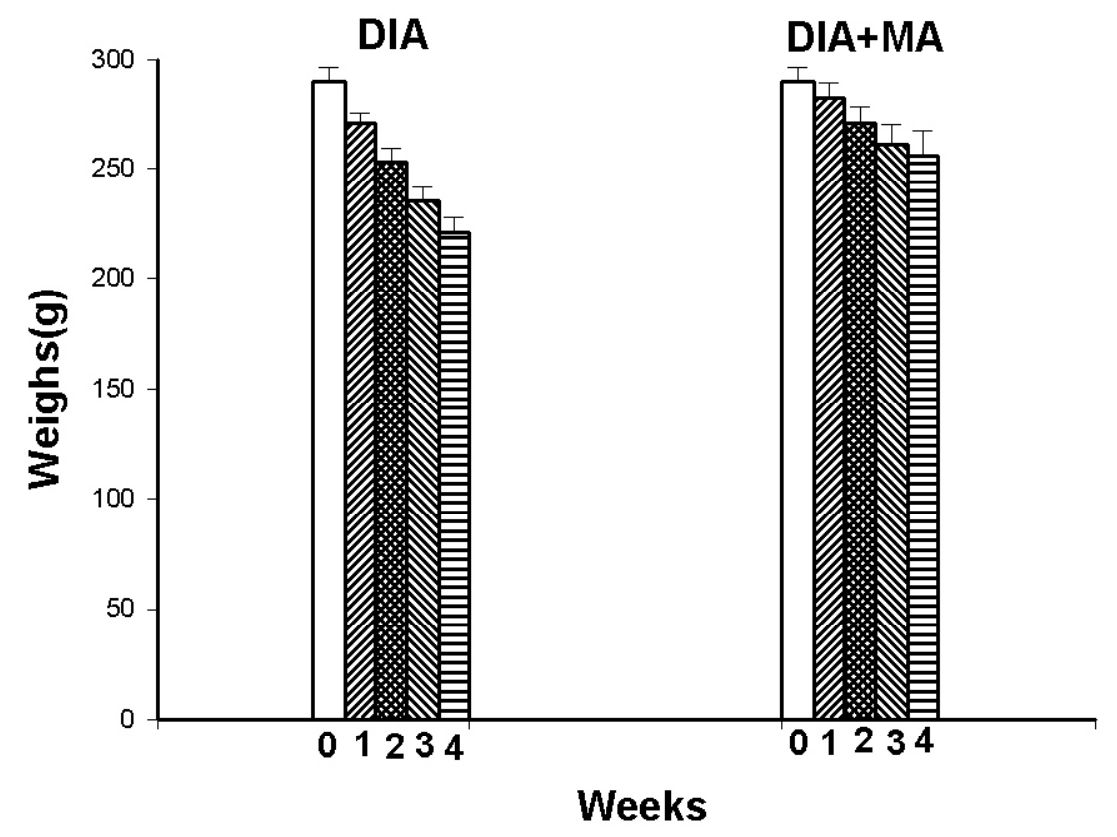

Figure 4 - The weighs of rats in DIA and DIA+MA groups during one month (mean \pm SEM)

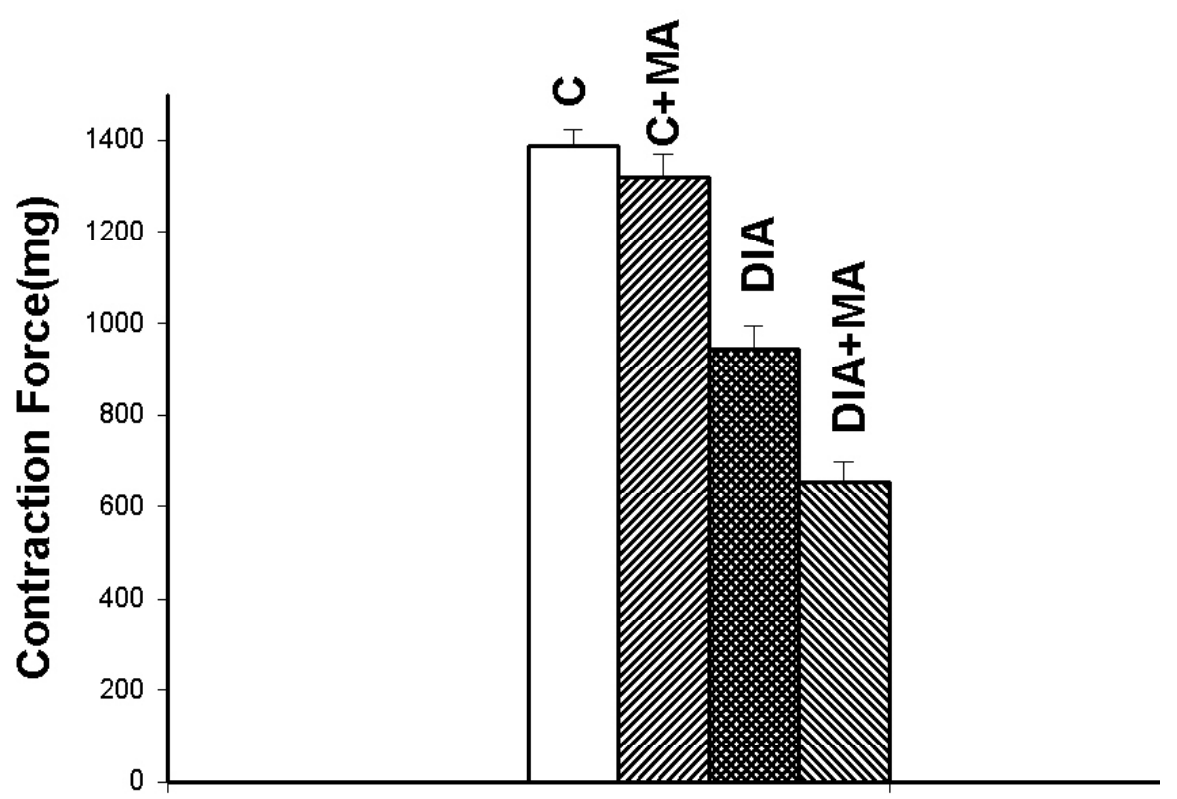

Figure 5 - The F responses to PE of thoracic aorta rings of rats in four groups (mean \pm SEM) 


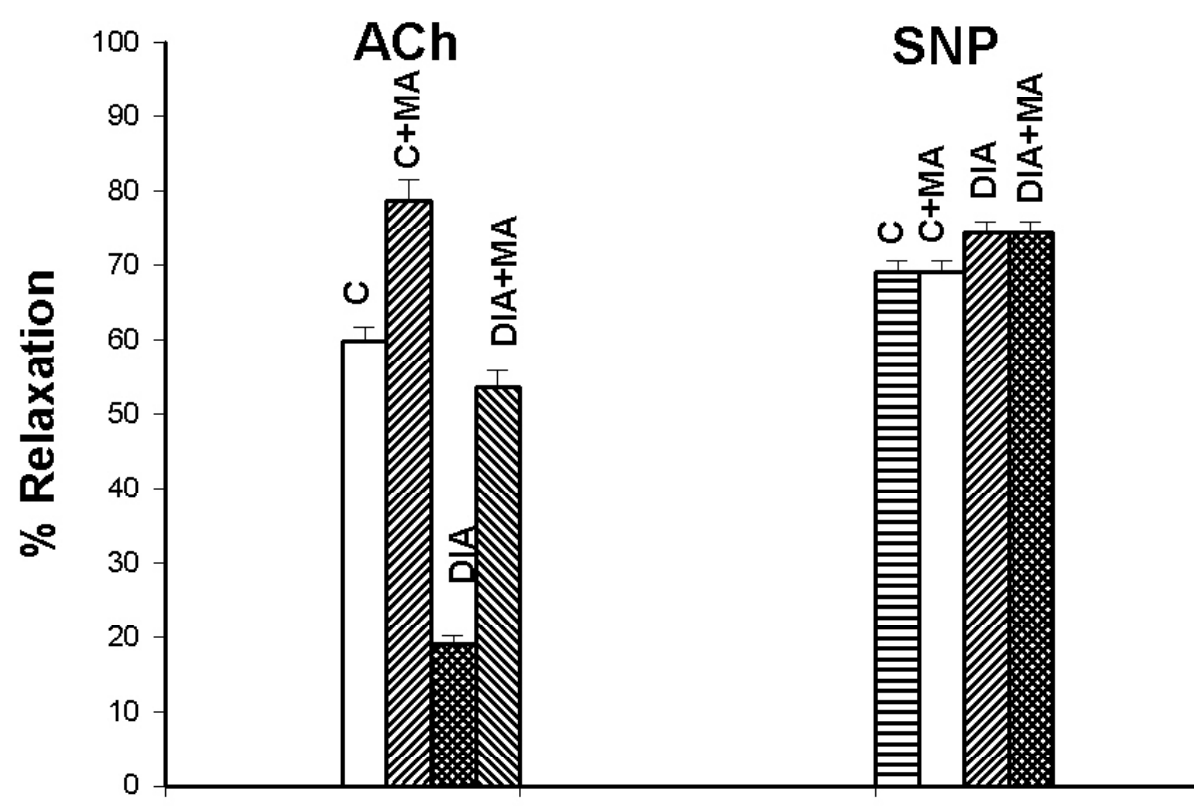

Figure 6 - The relaxation responses to ACh or SNP of thoracic aorta rings of rats in four groups (mean \pm SEM)

\section{DISCUSSION}

Whilst the weight loss observed in the $\mathrm{C}+\mathrm{MA}$ rats was attributed to symptoms developing secondary to stress, that in rats of the DIA+MA group it showed stress as an effective factor in addition to the typical symptoms developing in diabetic cases. For this reason stress factors needed to be investigated (Coudray et al., 1999; Behari et al., 1997; Laight et al., 1999; Peregrin et al., 2001).

The role of free radicals in the development of complications in diabetes is significantly great. The increase in the production of free radicals is due to glucose autooxidation, leukocyte activation, and the transition metals (Wolf et al., 1975). Specially, in diabetic patients with micro- and macro-vascular complications, the free radicals have been demonstrated to increase tissue injury whilst suppressing the levels of the various antioxidants (Velazquez et al., 1991). Free oxygen radicals and lipid peroxides are known to be responsible for the pathogenesis of most diseases including atherosclerosis, infectious disease and cancer (Yogu et al., 1984; Nihigaki et al., 1980). In individuals with normal metabolism the free oxygen radicals that are released to a limited extent are removed by the antioxidative defense systems which provide for the homeostasis of the organism. Free radicals and peroxides, despite their apparent similarities with diabetogenic agents are believed to play an important role in the relationship between nitric oxide formation and guanilate cyclase activity, peroxidase regulation, and prostaglandin synthesis (Wolf et al., 1993). In the present study positive effect of the chronic AC magnetic field exposure was observed on the endothelium dependent relaxation of the thoracic aorta preparations isolated from both the healthy and diabetic rats. However, no effect of the magnetic field was observed in relaxations independent of the endothelium. This positive effect of the magnetic field on relaxations suggests the role of endothelium-derived hyperpolarizing factor (EDHF) in addition to endothelium-derived relaxing factor (EDRF) (Chen et al., 1988; Taylor et al., 1988; Ignarro et al., 1988; Vahoutte et al., 1989; Kamata et al., 1989; Suzuki et al., 1982; Feletou et al., 1987; Griffith et al., 1986; Furchgott et al., 1983; Furchgott et al., 1980; Kuriyama et al., 1978). Thus the examination of the electrical response of the thoracic aorta preparations is necessary. Also, the magnetic field has been reported in the literature to positively affect the blood chemistry of the rats with diabetes and therefore serves as a new agent to be selected in the treatment of atherosclerosis. Whether chronic 
magnetic field exposure have a positive or negative effect on the thoracic aorta preparations of both healthy and diabetic rats can only be confirmed after examination of stress factors, free radicals, electrical responses of the thoracic aorta preparations, blood chemistry values, and histological sections. Studies are continuing in this regard.

\section{REFERENCES}

Behari, J. and Mathur, R. (1997), Exposure effects of static magnetic field on some physiological parameters of developing rats. Indian Journal of Experimental Biology, 35, 894-897.

Bellossi, A.; Pauvreau-Quillien, V.; Rocher, C. and Ruelloux, M. (1996), Effect of pulsed magnetic fields on cholesterol and triglyceride levels in rats study of field intensity and length of exposure. Z.Naturforsch, 51c, 603-606.

Bellossi, A.; Pouvreau-Quilien, V.; Rocher, C. and Reulloux, M. (1998), Effect of pulsed magnetic fields on triglyceride and cholesterol levels in plasma of rats. Panminerva Med., 40, 276-9.

Chen, G.; Suzuki, H. and Weston, A. H. (1988), Acetylcholine releases endothelium-derived hyperpolarizing factor and EDRF from rat blood vessels. Br. J. Pharmacol., 95, 1165-1174.

Coudray, C. F.; Rock, E.; Coudray, C.; Grzelkowska, K.; Braesco-Azais, V.; Dardevet, D. and Mazur, A. (1999), Lipid peroxidation and antioxidant status in experimental diabetes. Clinica Chimica Acta, 284, 31-43.

Feletou, M. and Vanhoutte, P. M. (1987), Endothelium dependent hyperpolarization of canine coronary smooth muscle. Br. J. Pharmacol., 93, 515-524.

Furchgott, R. F. (1983), Role of endothelium in responses of vascular smooth muscle. Circ. Res., 53, 557-573.

Furchgott, R. F. and Zwadzki, J. V. (1980), The obligatory role of endothelial cells in the relaxation of arterial smooth muscle by acetylcholine. Nature, 288, 373-376.

Griffith, T. M.; Edwards, D. H.; Newby, A. C.; Lewis, M. J. and Henderson, A. H. (1986), Production of endothelium derived relaxing factor is dependent on oxidative phosphorylation and extracellular calcium. Cardiovasc. Res., 20, 7-12.

Gordon, R. T. and Gordon, D. (1981), Selective resolution of plaques and treatment of atherosclerosis by biophysical alteration of "cellular" and "intracellular" properties. Medical Hypotheses, 7, 217-229.
Ignarro, L. J.; Byrns, R. E. and Wood, K. S. (1988), Biochemical and pharmacological properties of endothelium-derived relaxing factor and its similarity to nitric oxide radical. In: Vanhoutte, P. M. (Ed.). Mechanisms of Vasodilatation. New York : Raven Press. pp. 427-435.

Kamata, K.; Miyata, N. and Kasuya, L. (1989), Impairment of endothelium dependent relaxation and changes in levels of cyclic GMP in aorta from streptozotocin induced diabetic rats. $\mathrm{Br}$. $J$. Pharmacol., 97, 614-618.

Kuriyama, H. and Suzuki, H. (1978), The effects of acetylcholine on the membrane and contractile properties of smooth muscle cells of the rabbit superior mesenteric artery. Br. J. Pharmacol., 64, 493-501.

Laight, D. W.; Carrier, M. J. and Anggard, E. E. (1999), Endothelial cell disfunction and the pathogenesis of diabetic macroangiopathy. Diabetes Metab. Res. Rev., 15, 274-282.

Nihigaki, I.; Hogihara, M.; Hisomatw, M.; İzowa, Y. and Yoyi, K. (1980), Neurology. Peripheral Nerve Disorders: a Practical Approach. Boston : Butterworths. pp. 126.

Peregrin, A. T. and Guy, R. G. (2001), Recovery of microvascular responses during streptozotocininduced diabetes. European Journal of Pharmacology, 414, 63-70.

Suzuki, H. and Twarog, B. M. (1982), Membrane properties of smooth muscle cells in pulmonary arteries of the rat. Am. J. Physiol., 242, H900-H906.

Taylor, S. G.; Southerton, J. S.; Weston, A. H. and Baker, J. R. J. (1988), Endothelium-dependent effects of acetylcholine in rat aorta: a comparison with sodium nitroprusside and cromakalim. $\mathrm{Br} . \mathrm{J}$. Pharmacol., 94, 853-863.

Vanhoutte, P. I. M. and Shimokawa, H. (1989), Endothelium derived relaxing factor and coronary vasospasm. Circulation, 80, 1-9.

Velazquez, E.; Wincour, P. H.; Kestsven, P.; Alberti, K. G. M. M. and Laker, M. F. (1991), Relation of lipid peroxidase to macrovascular disease in type II diabetes. Diabetes Med., 8,752-758.

Wolf, S. P. (1993), Diabetes mellitus and free radicals. Br. Med. Bull., 49 : (3), 642-52.

Wolf, S. P.; Song, J. and Hunt, J. V. (1975), Protein glycation and oxidation stress in diabetes mellitus and ageing. Contemporary Issues in Endocrinology and Metabolism. New York : Churchill Livingstone Inc. v.1. pp. 223

Yogi, K. (1984), Increased lipid peroxides initiate atherogenesis. Bio Essays, 58-60. 